\title{
НАДЗОРНАЯ ФУНКЦИЯ ПРОКУРАТУРЫ (теоретический аспект)
}

\begin{abstract}
Аннотация. Предметом исследования является надзорная функция прокуратуры Российской Федерации. Объектом исследования является прокуратура РФ. Автор подробно рассматривает такие аспекты как место и функции органов прокуратуры при реализации которых выполняются задачи и достигаются цели, стоящие перед главным надзорным органом. В ходе историко-правового анализа показано, что функции прокуратуры формировались постепенно, параллельно формированию общественных отношений. Исходя из того, что прокуратура, в соответствии с законом - система органов, результативность и эффрективность её надзорной деятельности также должна быть системна, т.е. обеспечиваться продуктивными структурными и функциональными связями всех элементов системы прокурорского надзора. Методология исследования выстроена на базе анализа действующего законодательства в сфере прокурорского надзора, с применением ретроспективного историко-правового и доктринального анализа. Основными выводами проведения исследования являются: обоснование современного представления о функции прокурорского надзора. Выявлены тенденции развития надзорной функции российской и советской прокуратуры, сделан вывод об исторически обусловленной нецелесообразности её сокращения. Новизна в исследовании заключается в том, что по результатам рассмотрения прокурорского надзора как системной деятельности, введено и пояснено понятие «механизм прокурорского надзора», выявлена дискуссионность и противоречивость ряда позиций, содержащихся в литературе. Особое внимание уделено вопросам приоритетов надзорной деятельности. Данный вопрос критически рассмотрен на примере противодействия терроризму, надзора за так называемыми резонансными делами, понятие которых рекомендовано устранить из правоприменительной практики. Сделан вывод о фрагментарности исследования отдельных элементов механизма прокурорского надзора, «тематическое» и даже конъюнктурное восприятие надзора, наличии кампанейщины, особенно по новым приказам Генерального прокурора, актуализирующим на данный момент определенные сферы и объекты надзора.
\end{abstract}

Ключевые слова: прокурорский надзор, прокуратура, надзорная, функция, объект, надзора, механизм, прокурорского надзора, закон, функции государства.

Abstract. The research subject is the supervisory function of the Russian Prosecution Service. The research object is the Prosecution Service of the Russian Federation. The author considers such aspects as the role and the function of prosecution agencies which help to implement the tasks and to achieve the objectives of the general prosecution agency. The author applies the method of historical and legal analysis to prove that the functions of the Prosecution Service have been forming gradually, together with the social relations formation. In terms of the fact that the Prosecution Service is, according to the law, a system of agencies, the effectiveness of its supervisory activities should also have a system character, i.e. it should be ensured by the productive structural and functional linkages of all elements of the prosecutor's supervision system. The research methodology is based on the analysis of the current legislation in the sphere of prosecutor's supervision via use of the retrospective historical and legal and doctrinal analysis. The author substantiates the modern understanding of the function of prosecutor's supervision, reveals the development trends of the supervisory function of the Russian and the Soviet Prosecution Service, and concludes about the historical grounds of impracticality of its reduction. The novelty of the research consists in the introduction and explanation of the term "prosecutor's supervision mechanism"; the author reveals the disputable and contradictory character of some provisions contained in the related literature. Special attention is paid to the issues of supervisory activity priorities. This problem is studied using the example of struggle against terrorism and supervision over the so-called resonant cases. The author advises eliminating such a definition from the law enforcement practice. The author concludes about the fragmentarity of particular elements of prosecutor's supervision mechanism studying, about the topical and even opportunistic understanding of supervision, the stop-and-go style, especially in the new decrees of the Prosecutor General actualizing particular spheres and objects of supervision.

Key words: prosecution service, supervisory, function, object, supervision, mechanism, prosecutor's supervision, law, state functions, prosecutor's supervision.

$\Phi$ ункции государства и его органов производны от политического режима и государственного устройства, а государственные органы объединены в единую систему, где органы прокуратуры составляют особую группу, имеющую особые функции. Конституция РФ не содержит полного перечисления функций прокуратуры. При этом путем реализации функций выполняются за- 


\section{Административное и муниципальное право 5 (101) • 2016}

дачи и достигаются цели, стоящие перед главным надзорным органом. Цели и задачи прокурорского надзора, как обоснованно отмечает 0. И. Куленко, две категории, тесно связанные между собой, но и отличные друг от друга. Так, цели - это результат, на достижение которого направлена деятельность прокуратуры, включая и прокурорский надзор[13, c. 51], в свою очередь, цели которого определяются статусом прокуратуры, ее местом и ролью в правовой системе и государстве. Формализация целей содержится в Конституции России и Федеральном законе от 17 января 1992 г. № 2202-1 «О прокуратуре Российской Федерации», а также в отраслевом законодательстве и подзаконных актах.

Активные научные дискуссии о роли и месте прокуратуры в Российской Федерации, начавшись с конца 1980-х годов, продолжаются и сейчас. Попрежнему есть разногласия в основном вопросе - о сущности прокуратуры и её базовых функциях. Ответа на него нет и в Конституции. В связи с этим поиски концептуальной модели деятельности российской прокуратуры продолжаются. Исследователи разделились на группы, где доминируют три позиции: прокуратура - орган надзора; прокуратура - институт государственного обвинения; прокуратура сочетает первое и второе.

В ряде работ российская прокуратура обоснованно представляется сложной иерархической, системной организацией по реализации властных полномочий. В. Д. Кошлевский считает, что «в этом учреждении [прокуратуре] находят свое выражение индивидуальные, групповые и государственные интересы» $[12$, с. 6], с чем сложно согласиться, особенно в части «индивидуальных и групповых интересов».

Помимо важного теоретического значения, данный спор важен в практическом плане, оптимального структурирования надзорных органов. Почти столетие назад большевики, отрицая наследие царского режима, должны были бы упразднить прокуратуру как антинародный орган. В то же время, распыление функций контроля по группе непрерывно реформируемых советских органов, отсутствие четких правомочий по устранению нарушений закона, нередко прямая подчиненность поднадзорных органов, рост преступности при отсутствии координатора борьбы с ней стали весомыми аргументами. Исследователи пришли к выводу о том, что царская прокуратура ликвидирована, так как «была не нужна», а советская была создана путем «опытного выявления и установления... практической необходимости создания и включения в состав государственных органов...»[19, с. $39 ; 17$, с. 60]. При этом новая советская прокуратура имела и новое содержание, принципы организации, задачи и функции[10, с. 46]. Таким образом, потребность в прокуратуре вытекает из любых общественных отношений и не зависит от политического режима. В частности, в Советской России, принципиально новом по социальному строю государстве, все же возникла необходимость создания специального надзорного органа - прокуратуры, что свидетельствует об определенной универсальности, востребованности прокуратуры при любом общественном строе и типе государства. В связи с этим при любых реформах государственного устройства прокуратура востребована, что определяет повышенную актуальность и значимость исследований надзорной функции прокуратуры как объекта историко-правового анализа.

Примечательно, что советская власть не определяла сразу директивно, а допускала активные дискуссии о положении и месте прокуратуры. Таким образом, функции прокуратуры не могут быть изначально жестко заданы, а формируются постепенно, параллельно формированию общественных отношений. Уже на заре становления советской правовой системы, сформировались две позиции (дискуссионные в отдельных частях до сих пор) по обсуждавшемуся вопросу:

1) подчинение прокуратуры, «с одной стороны Центру (соответствующему наркомату), с другой стороны - местному губисполкому»[14, с. 197]. При этом зависимость от местных органов состояла в назначении прокуроров, а также во внесении представлений о нарушениях законности в Наркомюст через губернские отделы юстиции.

2) прокуратура - самостоятельный жестко вертикально централизованный независимый орган государства.

В. И. Ленин, занимая позицию, принятую и сегодня, был против подчинения прокуратуры местной власти и настаивал только на подчинении «Центру в лице генерал-прокурора»[14, с. 201]. Аргументация данного подхода содержалась в письме В. И. Ленина «О «двойном» подчинении и законности» от 22 мая 1922 г., где изложены базовые принципы организации и деятельности прокуратуры. Именно этот документ был положен в основу формирования советской прокуратуры.

Споры о функциях прокуратуры и сегодня нередко имеют политический характер. В этой связи C.M. Казанцев выдвигает весьма спорную, на наш взгляд, гипотезу о том, что «прокуратура, а российская в особенности, по своей сути всегда была институтом консервации общественных отношений, а не реформирования общественного и государственного строя»[11, с. 7]. Автор аргументирует свою позицию неизбежностью конфликтов между социальными силами, стремящимися к «новому обществу» (не пояснено, что имеет автор ввиду), и при этом, выходящими за законные рамки дей- 
ствующего законодательства, и прокуратурой, которая стоит «на страже существующего закона».

В данном случае автор рассматривает конфронтационную модель развития отношений, которая не является единственной и неизбежной, так как процессы политического реформирования могут идти и мирным, вполне законным путем. Кроме того, указанная позиция прямо связывает прокуратуру с политической деятельностью (что мы, к сожалению, нередко наблюдаем в современной практике), тогда как действующее законодательство ставит прокуратуру вне политики.

В современных исследованиях предлагаются и комплексные подходы. Так, В.Д. Кошлевский подчеркивает, что современному состоянию российской государственной власти в России отвечало бы сочетание инструментально-организационного, институционально-функционального и ассоциативного подходов в государственном управлении, что, по мнению автора, «обеспечит тесную координацию внутренних и внешних усилий государства по защите интересов общества». Отсюда делается вывод о необходимости обсуждения вопроса о задачах и функциях прокуратуры, что даст возможность уточнить её статус и место в государственном механизме и откорректировать действующее законодательство, регламентирующее деятельность данного института[12, с. 6].

В 2003 г. С.М. Казанцев отмечал стремление политических кругов и общественного мнения «решительно реформировать российскую прокуратуру», чем объяснялась актуальность «вопроса о роли и значении этого государственного института в новых общественных условиях»[11, с. 9]. Сегодня такие задачи не ставятся. От прокуратуры требуется:

- повысить эффективность надзора за расследованием преступлений, прежде всего террористической и экстремисткой направленности;

- активно включиться в формирование «цивилизованных отношений в миграционной сфере»;

- взаимодействовать с контрольными и надзорными органами, противодействуя коррупции и снижая административное давление на бизнес[8].

Кроме того, в рамках общего надзора приоритетами в приказах Генерального прокурора названы: надзор за исполнением финансового, таможенного, банковского, налогового, антимонопольного законодательства; надзор за исполнением законов в социальной сфере, за законностью в сфере государственного строительства, за соблюдением трудового законодательства (предупреждение невыплат (задержек) зарплат) и т.п. В литературе по прокурорскому надзору выявляется закономерность. Автор, исследуя свое направление надзора, именно его считает и выделяет как особо важное, приоритетное и «основное»[22, с. 26]. В целом, приоритет отдан наиболее социально и экономически значимым сферам. Очевидно, что смысл выделения приоритетных направлений общего надзора состоит в акцентах на остро актуальных проблемах. В то же время, в приказах Генерального прокурора нередко встречаются указания по усилению надзора по так называемым «резонансным делам», понятия которых УПК РФ не предусмотрено. Формально данный подход нарушает конституционный принцип равенства, так как одним делам уделяется особое внимание, что законом не предусмотрено. Понятие «резонансного дела» должно быть внесено законодателем в процессуальное законодательство либо исключено (предпочтительно) из ведомственных приказов, не только прокуратуры.

Что касается очевидных приоритетов противодействия терроризму, то в данном случае эффективность прокурорского надзора вызывает вопросы. Со значительным опозданием, лишь в 2007 г. управление Генеральной прокуратуры РФ по надзору за исполнением законов о федеральной безопасности было реформировано и стало Управлением по надзору за исполнением законов о федеральной безопасности, межнациональных отношениях и противодействии экстремизму[5]. В то же время, нормативно деятельность Управления обеспечена не была. Соответствующие приказы об организации прокурорского надзора за исполнением законодательства о противодействии терроризму и экстремизму были подписаны лишь через два года. Только тогда был нормативно закреплен приоритет данных видов надзора[2]. Приказы ориентировали прокуроров в относительно новой сфере, и уже в 2010 г. ими было выявлено более 100 тыс. нарушений законодательства о противодействии терроризму[6]. В то же время, крупные теракты в аэропорту «Домодедово», в московском метро, в Волгограде, свидетельствовали о недостаточной эффективности такой работы.

Исходя из того, что прокуратура, в соответствии с законом - система органов, сегодня результативность и эффективность её надзорной деятельности также должна быть системна, т.е. обеспечиваться продуктивными структурными и функциональными связями всех элементов системы прокурорского надзора. Здесь следует исходить из положений общей теории права, где анализ механизма правового регулирования позволяет выявить как и какими правовыми средствами достигаются цели прокурорского надзора[16, с. 370]. В частности, нормами права определяются полномочия прокуроров, условия их реализации, устанавливаются правовые средства, порядок их использования, уточняются права и обязанности поднадзорных субъектов. В данном случае сам ме- 


\section{Административное и муниципальное право 5 (101) • 2016}

ханизм функционирования органов прокуратуры в сфере надзора показывает динамическую сторону анализируемого вида деятельности. Очевидно, что лучшие законы - лишь декларация без специального механизма контроля их исполнения. Изучение и последующее совершенствование такого механизма даст возможность выявить и укрепить взаимосвязь элементов надзорной деятельности.

Собственно дефиниция «механизм прокурорского надзора» почти не применяется и доктринально не включена в понятийный оборот, хотя все основные элементы такого механизма описаны и активно изучаются. Прежде всего, это касается надзорных полномочий и средств. В литературе они рассматриваются в основном применительно к частным отраслям надзора. Так, В.Ю. Шобухин, анализируя статус прокуратуры применительно к базовым отраслям надзора, уделяет внимание полномочиям прокурорских работников, лишь упоминая используемые ими правовые средства[22]. В другом источнике правовые средства раскрыты шире, но явно в ущерб полномочиям[7, с. 206]. Фрагментарный подход к анализу элементов механизма прокурорского надзора отличается детализацией прав и обязанностей прокурора. Так, в учебной литературе с недавних пор принято выделять главы «Средства прокурорского надзора» [9, с. 173].

В то же время, исследование отдельных элементов механизма надзора органов прокуратуры все ещё фрагментарно, а прокурорский надзор воспринимается более «тематически», чем целостно. На практике это оборачивается кампанейщиной, особенно по новым приказам Генерального прокурора, когда по актуальным на данный момент объектам надзора проявляется излишнее рвение, либо полное отсутствие интереса относительно других (например, после решений о снижении административного давления на бизнес 2008-2009 годов).

Отрасли надзора, указанные в ст. 1 Закона «0 прокуратуре...» должны считаться приоритетными. В то же время, развитие государства и общества влияет на перечень таких направлений. В теории прокурорского надзора устоялось мнение, согласно которому выделение ряда актуальных направлений общего надзора делается необходимо для надлежащей организации работы[21, с. 101]. Данная позиция в литературе связывается с особенностями предмета надзора и с полномочиями, предоставленными законом прокурору для выполнения надзорной функции [20, с. 8]. Отсюда организация надзорной деятельности прокуратуры тесно взаимосвязана с общей эффективностью механизма прокурорского надзора, понятие которого является системообразующим для целостного понимания прокурорского надзора. Таким образом, механизм прокурорского надзора следует считать системой полномочий, средств и действий по обеспечению точного, безусловного и единообразного исполнения законов.

Механизм прокурорского надзора единообразен для всех его направлений, так как задан общим государственно-правовым назначением и местом в правоохранительной системе. Здесь целесообразно выделить ряд этапов. На первом формируются прокурорско-надзорные правоотношения, а в их рамках устанавливается юридическая связь между субъектами. Одним из таких субъектов принято считать прокурора, что в целом бесспорно, но все же требует конкретизации, так как понятие «прокурор» трактуемо. В узком смысле - это прокуроры в статусе руководителей прокуратуры, но в широком, как и целесообразно трактовать при анализе статуса прокурора как субъекта прокурорского надзора, это совокупность должностных лиц, поименованная в ст. 54 Закона «0 прокуратуре...».

Органы, организации и учреждения, их должностные лица, на чьи действия и правовые акты распространен прокурорский надзор, следует считать его объектами, так как их деятельность есть предмет прокурорского надзора. Указанные органы и лица не могут быть субъектами прокурорского надзора, даже будучи вовлечены в надзорную деятельность. В то же время, в боле общем понимании, являясь субъектами прокурорско-надзорных отношений, они могут быть отнесены к поднадзорным субъектам. В связи с этим, субъекты прокурорсконадзорных правоотношений, будучи элементом механизма функционирования органов прокуратуры в сфере надзора, дифференцируются на субъектов прокурорского надзора и поднадзорных субъектов. Обе категории находятся в диалектической взаимосвязи, следуя которой многообразие и большое число последних не могут не обуславливать широкий подход к составу первых. Выявление такой взаимосвязи может показаться источником предложения о сокращении числа участников прокурорско-надзорных правоотношений. Так, в проекте федерального закона «0 внесении изменений и дополнений в ФЗ «0 прокуратуре РФ» данное предложение было реализовано путем исключения надзора за исполнением законов органами управления и руководителями коммерческих и некоммерческих организаций, а также надзора за их правовыми актами[4]. Данная инициатива, реализованная в свое время при создании министерской системы Александром I, имела отрицательный результат, так как исключительно ведомственный контроль себя не оправдал. Вот и сегодня данная инициатива не была поддержана. В частности Н.В. Мельников, обоснованно указал на необходимость вмешательства прокуратуры, «которая является поисковым органом и не связана, как суд, приводным ремнем искового производства» [15, c.38]. При таком эвристическом характере деятель- 
ности прокуратуре ежедневно необходима актуальная и релевантная информация, которой, как правило, недостаточно, соответственно страдает и аналитическая работа.

В современных крайне сложных условиях геополитического противостояния, санкций и неблагоприятной экономической конъюнктуры, сложности многообразия объектов надзора, необходимо преодолевать не путем механического сужения их круга, а научно обоснованным и концептуально проработанным выделением специфики территории, отраслей, приоритетных направлений надзора с последующим распределением обязанностей между прокурорскими работниками. Данная задача по сути организационная и решается «отладкой» механизма надзорной деятельности.

Для уточнения состава поднадзорных субъектов прокурор полномочен истребовать информацию от органов государственной власти и местного самоуправления, регистрирующих и налоговых органов, банков и т.п. Для обеспечения надлежащего уровня информированности прокуратуры неоднократно ставилась задача налаживания взаимодействия с указанными органами так, чтобы необходимые сведения поступали в прокуратуру регулярно[3]. При этом акцент всегда делался на взаимодействии прокуратуры с контролирующими органами, так как их возможности и огромный объем информации дают возможность прокурорам иметь адекватное представление о законности на подконтрольных объектах[9, с. 276]. Адекватное взаимодействие, собственно, и дает характеристику качества механизма прокурорского надзора.

Информационное обеспечение включает как поиск и сбор, так и аналитическую работу, необходимую для выявления причин нарушений и определения мер их превенции. Анализ информации дает возможность прокурору точнее определить содержание своих мероприятий, планировать на перспективу, в частности и проверки, которые необходимо провести. Таким образом, надзорный механизм прокуратуры опирается на систематический и полный сбор, накопление, обработку и интерпретацию информации о состоянии законности. Результатом этой работы становится выбор поднадзорных субъектов, а также средств реагирования.

Реализация надзорных полномочий ведется законодательно установленными правовыми средствами, под которыми принято понимать предусмотренные законодательством формы реализации полномочий прокурора, направленные на выявление, устранение и предупреждение нарушений закона[18, с. 140]. Таким образом, следующая фаза работы прокурорского надзорного механизма реализуется в форме конкретных действий по установлению фактов правонарушения, лиц, его совершивших, способа его совершения, размера ущерба и обстоятельствах, способствующих совершению правонарушения. На базе полученной информации о нарушении законности прокурор принимает решение о проверке поднадзорного объекта.

В современных условиях сохраняет актуальность вопрос о роли и месте прокуратуры в Российской Федерации, бывший предметом научных дискуссий ещё в период активного реформирования правовой системы России, с конца 1980-х годов. По-прежнему не решен основной вопрос - о сущности прокуратуры и её базовых функциях. Ответа на него нет и в Конституции. В связи с этим поиски концептуальной модели деятельности российской прокуратуры продолжаются. Исследователи разделились на три группы, где, соответственно, доминируют три позиции: прокуратура - орган надзора; институт государственного обвинения; сочетает первое и второе. На практике преобладает третья позиция, которая требует научного обоснования.

Надзорная функция всегда «отставала» от функции гособвинения, которая считалась приоритетной в прокуратурах и сходных институтов развитых стран, у которых Россия заимствовала политико-правовой опыт. Следует учитывать, что формирование и развитие прокуратуры, реализация её надзорной функции лежали в основе формирования в российском авторитарном (периодами - тоталитарном) правосознании политически заданной идеи законности.

\section{Библиография:}

1. Федеральный закон от 17.01.1992 N 2202-1 (ред. от 28.11.2015) «0 прокуратуре Российской Федерации»// Собрание законодательства РФ. 1995. № 47. Ст. 4472; 2015. № 48 (часть I). Ст. 6720.

2. Приказ Генерального прокурора от 19.11.2009 г. № 362 «Об организации прокурорского надзора за исполнением законодательства о противодействии экстремистской деятельности» // Генеральная прокуратур РФ Официальный сайт: www.genproc.gov.ru

3. Приказ Генерального прокурора РФ от 7 декабря 2007 г. № 195 «Об организации прокурорского надзора за исполнением законов, соблюдением прав и свобод человека и гражданина»// Официальный сайт Генеральной прокуратуры РФ.

4. Законопроект «0 внесении изменений и дополнений в Федеральный закон «0 прокуратуре Российской Федерации» (авторы - Похмелкин В.В. и др.)// Официальный сайт государственной Думы.

5. Положение об управлении по надзору за исполнением законов о федеральной безопасности, межнациональных отношениях и противодействии экстремизму, утв. Генеральным прокурором РФ 05.12.2007 г. // Официальный сайт Генеральной прокуратуры РФ: www.genproc.gov.ru 


\section{Административное и муниципальное право 5 (101) • 2016}

6. Доклад Генерального прокурора на заседании Совета Федерации Федерального Собрания РФ от 24.04.2011 г. «0 состоянии законности и правопорядка в 2010 г. и о проделанной работе по их укреплению»// Официальный сайт Генеральной прокуратуры РФ: www.genproc.gov.ru

7. Бессарабов В.Г. Прокурорский надзор: учеб. М.: ТК Велби, Изд-во Проспект. 2006. 536 с.

8. Выступление Руководителя Администрации Президента России С. Иванова на торжественном заседании, посвящённом 292-й годовщине российской прокуратуры 10 января 2014 г.// Президент России. Официальный сайт http://www.kremlin.ru/events/administration/20045

9. Григорьев В.Н. Прокурорский надзор: учеб./ В.Н.Григорьев, А.В. Победкин, В.Н. Яшин, В.Н. Калинин М.: Эксмо. 2006. $544 \mathrm{c}$.

10. История советской прокуратуры в важнейших документах/ Под ред. К. А. Мокичева. М., 1952. 388 с.

11. Казанцев С. М. Прокуратура Российской империи: историко-правовое исследование: дисс... д-ра юрид. наук. 12.00.01. СПб., 2003. 455 с.

12. Кошлевский В. Д. Место и роль прокуратуры в механизме российского государства: автореф. дисс... канд. юрид. наук: 12.00.01. Саратов, 2008. 22 с

13. Куленко О.И. Функции российской прокуратуры и их конституционная природа// Вестник Челябинского государственного университета. 2008. №8. С. 50-56.

14. Ленин В.И. О «двойном» подчинении и законности// Полн. собр. соч. 5-е изд. Т. 45. С. 197-201.

15. Мельников Н.В. Прокурорский надзор - самостоятельная форма осуществления прокурорской власти в России// Государство и право. 2003. № 5. С. 34-41.

16. Морозова Л.А. Теория государства и права. Изд. 3-е перераб. и доп. М.: Эксмо. 2010. 384 с.

17. Мурашин Г.А. Органы прокуратуры в механизме советского государства. Киев, 1972. 178 с.

18. Синельщиков Ю.П. Настольная книга прокурора. М., Экслит, 2002. 850 с.

19. Советская прокуратура. История и современность. М., 1977. 244 с.

20. Трикс А.В. Справочник прокурора СПб: Питер. 2007. 160 с.

21. Шобухин В.Ю. Статус российской прокуратуры. СПб: ООО «Университетский издательский консорциум «Юридическая книга». 2009. 244 с.

22. Шобухин В.Ю. Надзор за исполнением законов какодного из основныхнаправлений деятельности прокуратуры // Правоведение. 2007. № 6. С. 24-33.

\section{References (transliterated):}

1. Federal'nyi zakon ot 17.01.1992 N 2202-1 (red. ot 28.11.2015) «O prokurature Rossiiskoi Federatsii»// Sobranie zakonodatel'stva RF. 1995. № 47. St. 4472; 2015. № 48 (chast' I). St. 6720.

2. PrikazGeneral'nogo prokurora ot 19.11.2009g. № 362 «Ob organizatsiiprokurorskogo nadzoraza ispolneniem zakonodatel'stva o protivodeistvii ekstremistskoi deyatel'nosti» // General'naya prokuratur RF Ofitsial'nyi sait: www.genproc.gov.ru

3. Prikaz General'nogo prokurora RF ot 7 dekabrya 2007 g. № 195 «Ob organizatsii prokurorskogo nadzora za ispolneniem zakonov, soblyudeniem prav i svobod cheloveka i grazhdanina»// Ofitsial'nyi sait General'noi prokuratury RF.

4. Zakonoproekt «0 vnesenii izmenenii i dopolnenii v Federal'nyi zakon «0 prokurature Rossiiskoi Federatsii» (avtory Pokhmelkin V.V. i dr.)// Ofitsial'nyi sait gosudarstvennoi Dumy.

5. Polozhenie ob upravlenii po nadzoru za ispolneniem zakonov o federal'noi bezopasnosti, mezhnatsional'nykh otnosheniyakh i protivodeistvii ekstremizmu, utv. General'nym prokurorom RF 05.12.2007 g. // Ofitsial'nyi sait General'noi prokuratury RF: www.genproc.gov.ru

6. Doklad General'nogo prokurora na zasedanii Soveta Federatsii Federal'nogo Sobraniya RF ot 24.04 .2011 g. «0 sostoyanii zakonnosti i pravoporyadka v 2010 g. i o prodelannoi rabote po ikh ukrepleniyu»// Ofitsial'nyi sait General'noi prokuratury RF: www.genproc.gov.ru

7. Bessarabov V.G. Prokurorskii nadzor: ucheb. M.: TK Velbi, Izd-vo Prospekt. 2006. 536 s.

8. Vystuplenie Rukovoditelya Administratsii Prezidenta Rossii S. Ivanova na torzhestvennom zasedanii, posvyashchennom 292-i godovshchine rossiiskoi prokuratury 10 yanvarya 2014 g.// Prezident Rossii. Ofitsial'nyi sait http://www.kremlin. $\mathrm{ru} /$ events/administration/20045

9. Grigor'ev V.N. Prokurorskii nadzor: ucheb./ V.N.Grigor'ev, A.V. Pobedkin, V.N. Yashin, V.N. Kalinin M.: Eksmo. 2006.544 s.

10. Istoriya sovetskoi prokuratury v vazhneishikh dokumentakh/ Pod red. K. A. Mokicheva. M., $1952.388 \mathrm{s.}$

11. Kazantsev S. M. Prokuratura Rossiiskoi imperii: istoriko-pravovoe issledovanie: diss... d-ra yurid. nauk. 12.00.01. SPb., 2003. $455 \mathrm{c}$.

12. Koshlevskii V. D. Mesto i rol' prokuratury v mekhanizme rossiiskogo gosudarstva: avtoref. diss... kand. yurid. nauk: 12.00.01. Saratov, 2008. $22 \mathrm{~s}$

13. Kulenko O.I. Funktsii rossiiskoi prokuratury i ikh konstitutsionnaya priroda// Vestnik Chelyabinskogo gosudarstvennogo universiteta. 2008. №8. S. 50-56.

14. Lenin V.I. O «dvoinom» podchinenii i zakonnosti// Poln. sobr. soch. 5-e izd. T. 45. S. 197-201.

15. Mel'nikov N.V. Prokurorskii nadzor - samostoyatel'naya forma osushchestvleniya prokurorskoi vlasti v Rossii// Gosudarstvo i pravo. 2003. № 5. S. 34-41.

16. Morozova L.A. Teoriya gosudarstva i prava. Izd. 3-e pererab. i dop. M.: Eksmo. 2010. $384 \mathrm{~s}$.

17. Murashin G.A. Organy prokuratury v mekhanizme sovetskogo gosudarstva. Kiev, 1972. 178 c.

18. Sinel'shchikov Yu.P. Nastol'naya kniga prokurora. M., Ekslit, 2002. $850 \mathrm{~s}$.

19. Sovetskaya prokuratura. Istoriya i sovremennost'. M., 1977.244 s.

20. Triks A.V. Spravochnik prokurora SPb: Piter. 2007. $160 \mathrm{~s}$.

21. Shobukhin V.Yu. Status rossiiskoi prokuratury. SPb: 000 «Universitetskii izdatel'skii konsortsium «Yuridicheskaya kniga». 2009. $244 \mathrm{c}$

22. Shobukhin V.Yu. Nadzor za ispolneniem zakonov kak odnogo iz osnovnykh napravlenii deyatel'nosti prokuratury // Pravovedenie. 2007. № 6. S. 24-33. 